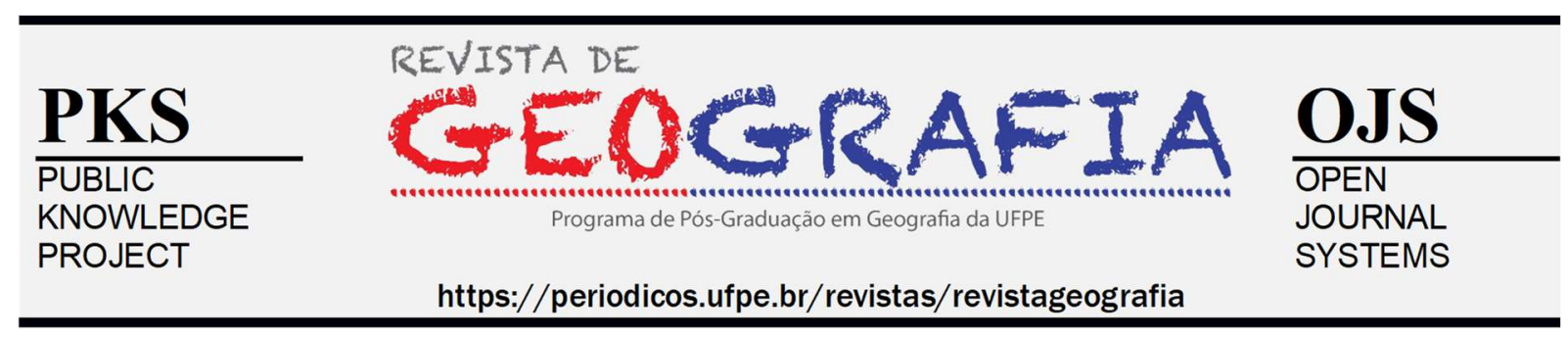

\title{
QUALIDADE DE ATERRO DE RESÍDUOS NA COSTA DO DESCOBRIMENTO
}

\author{
Ana Luísa Santos de Carvalho', Raiane da Silva Cruz², Leonilton Cagy Silva ${ }^{3}$, Elfany Reis do \\ Nascimento Lopes ${ }^{4}$, Fabrício Berton Zanchi ${ }^{5}$
}

\begin{abstract}
${ }^{1}$ Centro de Formação em Ciências Ambientais (CFCam). Programa de Pós-Graduação em Ciências e Tecnologias Ambientais. Universidade Federal do Sul da Bahia (UFSB). Instituto de Educação, Ciência e Tecnologia da Bahia - Campus Porto Seguro. E-mail: analuisascarvalho@gmail.com

${ }^{2}$ Centro de Formação em Ciências Ambientais (CFCam). Universidade Federal do Sul da Bahia (UFSB). Email: raianehenriques1@gmail.com

${ }^{3}$ Centro de Formação em Ciências Ambientais (CFCam). Programa de Pós-Graduação em Ciências e Tecnologias Ambientais. Universidade Federal do Sul da Bahia (UFSB). Instituto de Educação, Ciência e Tecnologia da Bahia - Campus Porto Seguro.E-mail: leocagy@gmail.com

${ }^{4}$ Laboratório de Geoprocessamento e Gestão Costeira (LAGGEC). Centro de Formação em Ciências Ambientais (CFCam). Universidade Federal do Sul da Bahia (UFSB).E-mail: elfany@csc.ufsb.edu.br

${ }^{5}$ Professor Adjunto do Centro de Formação em Ciências Ambientais (CFCam). Universidade Federal do Sul da Bahia (UFSB)E-mail: fabricio.berton@csc.ufsb.edu.br
\end{abstract}

Artigo recebido em 29/04/2020 e aceito em 14/07/2020

\begin{abstract}
RESUMO
A disposição final dos resíduos sólidos (RS) tornou-se um problema global para sociedade, meio ambiente e saúde pública. No contexto dos municípios turísticos a questão se torna ainda mais preocupante por conta do incremento na geração dos resíduos advindos do turismo. Nesse sentido, buscou-se identificar a situação do local de despejo final dos RS de Porto Seguro - BA. Para tal, adotou-se neste estudo o método de Índice de Qualidade de Aterros de Resíduos, proposto pela Companhia Ambiental do Estado de São Paulo (CETESB), que avalia as características, condições operacionais e da infraestrutura do local possibilitando classificar o aterro como adequado ou inadequado. Concomitantemente, realizou-se uma análise espacial para averiguação do local em relação aos aspectos socioambientais da região. Identificou-se na localidade a ausência de impermeabilização do solo, drenagem do chorume e gases, recobrimento dos resíduos e isolamento físico, comprometendo diretamente o ecossistema local. A análise espacial constatou a presença de núcleos habitacionais no entorno, a proximidade de hidrografias, entre elas o Rio Buranhém, que apresenta significativa importância para o território da Costa do Descobrimento. Assim, fica evidenciado a necessidade de estabelecer estratégias e adotar medidas que atendam a demanda local e assegurem a gestão e o manejo adequado dos resíduos.
\end{abstract}

Palavras-chave: Lixão; Análise Socioambiental; Resíduos Sólidos.

\section{LANDFILL QUALITY IN A DISCOVERY COAST}

ABSTRACT: The final disposal of solid waste (SW) has become a global problem for society, the environment and public health. In the context of tourist municipalities, the issue becomes even more worrying due to the increase in the generation of waste arising from tourism. In this sense, we sought to identify the situation of the final dumping site of the SW of Porto Seguro - BA. To this end, this method adopted the Waste Landfill Quality Index method, proposed by the Environmental Company of the State of São Paulo (CETESB), which assesses the characteristics, operational conditions and infrastructure of the site, making it possible to classify the landfill as appropriate or inappropriate. Concomitantly, a spatial analysis was carried out to ascertain the location in relation to the socio-environmental aspects of the region. The absence of waterproofing of the soil, drainage of 
leachate and gases, covering of residues and physical isolation was identified in the locality, directly affecting the local ecosystem. The spatial analysis found the presence of housing units in the surroundings, the proximity of hydrographs, among them the Buranhém River, which is of significant importance for the territory of the Costa do Descobrimento. Thus, the need to establish strategies and adopt measures that meet local demand and ensure the management and proper management of waste is evidenced.

Keywords: Dumping ground; Socioenvironmental Analysis; Solid waste.

\section{INTRODUÇÃO}

A produção e a gestão dos resíduos sólidos são desafiadoras e preocupantes na atualidade. A disposição final dos mesmos é um problema ambiental global e de saúde pública (GARCIA e CANDIANI, 2017). Esse problema surge com o período pós-industrial do capitalismo, por onde a diversificação e aumento dos resíduos corroborou para armazenados incorretos, provocando a contaminação dos solos, água e ar, bem como a proliferação de vetores e doenças na população (LIMA, 2015).

Essa problemática tem atraído a atenção da sociedade e, como resultado, diversas políticas públicas, estratégias e planos vem sendo desenvolvidos para a disposição dos Resíduos Sólidos Urbanos - RSU (EL-SALAM e ABU-ZUID, 2015). No Brasil, a Política Nacional de Resíduos Sólidos (PNRS), foi instituída como a legislação para normatizar os princípios, objetivos e instrumentos, além de orientar quanto à gestão integrada e o gerenciamento dos resíduos, às responsabilidades dos geradores e do poder público e dos instrumentos econômicos aplicáveis (BRASIL, 2010).

A PNRS visa diminuir os impactos negativos da disposição inadequada dos resíduos em lixões, determinando a disposição adequada nos municípios até 2014, que foram prorrogadas por sucessivas medidas governamentais. O Projeto de Lei $n^{\circ} 2.289 / 2015$ tem tramitado para determinar prazos distintos aos municípios de acordo com o tamanho da população, apoio técnico e financeiro para implementação dos locais de disposição (FERREIRA, 2017).

Conforme Assad e Siqueira (2016), os adiamentos sucessivos do encerramento de áreas de lixões e implantação de aterros sanitários demonstram a dificuldade de implementação de políticas públicas ambientais associadas a saúde, de forma que a gestão dos RSU não se mostra, no contexto brasileiro, uma prioridade para redução dos agravos socioambientais na sociedade, mesmo que a Política Nacional de Meio Ambiente (PNMA) proíba a sua existência (ASSAD E SIQUEIRA, 2016) 
No contexto internacional, os Estados Unidos produziram em 2015 cerca de 262 milhões de toneladas de RSU, sendo que deste total, 52,5\% de RSU foram depositados em aterros sanitários e as demais quantidades tiveram destinações como a compostagem, a reciclagem ou a queima destinada a obtenção de energia (USEPA, 2018). Já na em 14 países da União Europeia, Talalaj e Biedka (2016) apontaram que, em 2013, o montante destinado aos aterros sanitários ultrapassou os 50\%, sendo que 6 destes países o acumulado de RSU aos aterros foi superior a $75 \%$.

De acordo com o Diagnóstico do Manejo de Resíduos Sólidos no Brasil, foram coletados aproximadamente 60,6 milhões de toneladas de resíduos domiciliares durante o ano de 2017 ou cerca de 166 mil toneladas por dia nos municípios brasileiros (SNIS, 2019). Conforme o diagnóstico, do total de 3.556 municípios 36,9\% encaminham os resíduos domiciliares a aterros sanitários, $19,2 \%$ destinam ao lixão e 10,8\% para os aterros controlados.

A qualidade ambiental está diretamente relacionada com a disposição final dos resíduos, as condições e tempo de operacionalidade, proximidades com corpos d'água, disposição inadequada dos resíduos no solo e distância da fauna e flora dos aterros, exigindo estratégias que assegurem a prevenção do potencial poluidor dessa atividade (TALALAJ e BIEDKA, 2016).

A Avaliação de Impacto Ambiental (AIA) tem sido a principal estratégia de monitoramento do descarte de resíduos. Diversos estudos têm adaptado e aplicado metodologias para avaliar os impactos da disposição de resíduos sólidos, pois permite que impactos ambientais sejam previstos, tenham seus custos internalizados, podendo os riscos serem controlados e auxiliado a tomada de decisões (KRČMAR et al., 2018; TURRA et. al, 2017; ARRIETA et al., 2016; KINGSLEY et al., 2016; EL-SALAM e ABU-ZUID, 2015).

As pesquisas no setor de gestão de resíduos concentram-se em indicar áreas aptas para a instalação de aterros sanitários, utilizando geotecnologias e características naturais, sociais e econômicas das cidades, entretanto não avaliam as condições atuais do problema de descarte incorreto dos resíduos (BAIERLE et al., 2016; FELICORI et al., 2016; LOURENÇO et al., 2015). Os estudos realizados por Ferreira (2017), Garcia e Candiani (2017) e pela CETESB (2019) tem proposto metodologias para a realização de avaliações de impacto em lixões e aterros, funcionando como instrumentos indicativos de alterações no ambiente. 
Partindo da perspectiva de identificar as condições reais do descarte de resíduos e, baseando-se nas sucessivas modificações de prazos para implantação de aterros sólidos nos municípios brasileiros, requerendo o conhecimento potencial do despejo inadequado dos RSU, o estudo objetivou avaliar a qualidade do Aterro de Resíduos e a disposição final dos resíduos sólidos urbanos na Costa do Descobrimento.

\section{METODOLOGIA}

\section{Área de estudo}

O estudo foi desenvolvido na cidade de Porto Seguro, encontra-se localizado no extremo sul do Estado da Bahia, Brasil. O município é o único dos oito municípios do Território do Descobrimento que possuía aterro sanitário, do qual foi convertido a lixão a céu aberto. Nesse contexto, o estudo pautou-se na avaliação do atual local de disposição final dos resíduos sólidos urbanos de Porto Seguro - BA, situado ao norte do município (Figura 1).

Figura 1: Localização do lixão do município de Porto Seguro - BA.

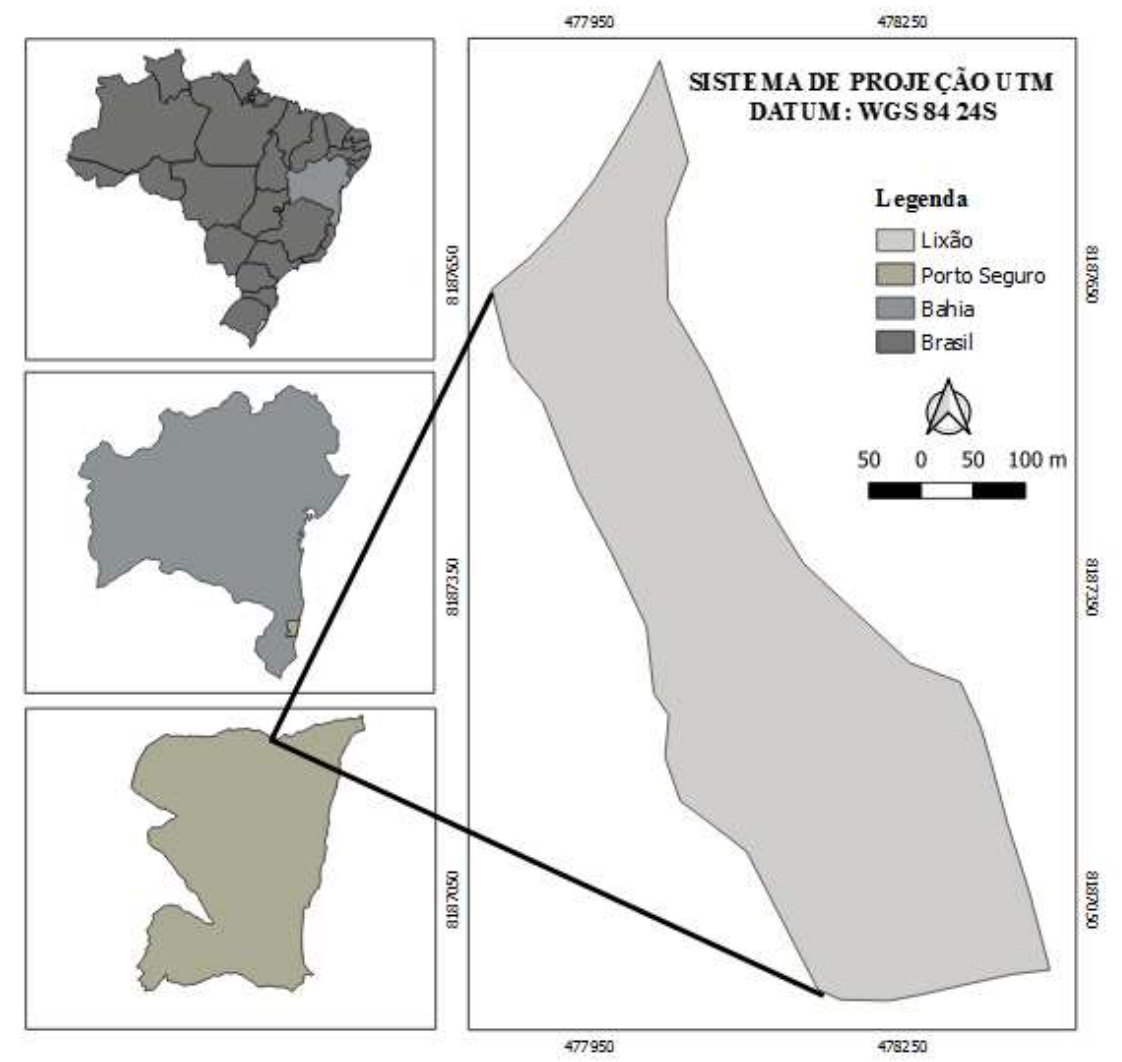

Fonte: elaborado pelos autores. 
Porto Seguro possui uma população estimada em 148.686 habitantes, área territorial de $2.287,085 \mathrm{~km}^{2}$ e densidade demográfica estimada em 52,42 hab $/ \mathrm{km}^{2}$ (IBGE, 2010).

A renda per capita média do município aumentou 123,24\% nas últimas décadas e obteve uma taxa média anual de crescimento média de 3,02\% entre os anos de 2000 e 2010 e Índice de Desenvolvimento Humano Médio era de 0,676 (IPEA E PNUD, 2013; IBGE, 2010). Conforme censo demográfico, 66,7\% de domicílios possuem esgotamento sanitário adequado e $70,1 \%$ de domicílios urbanos estão em vias públicas com arborização (IBGE, 2010).

Apresenta tipologia climática Köppen Af' do tipo tropical chuvoso sem estação seca; média mensal de pluviosidade acima dos $60 \mathrm{~mm}$ e anual inferior a $1500 \mathrm{~mm}$, temperatura no mês mais frio acima de $18{ }^{\circ} \mathrm{C}$ e no mês mais quente acima dos $22^{\circ} \mathrm{C}$. O município se encontra em solos advindos de sedimentos pedogeneizados do grupo geológico Barreiras, predominando nos solos oxídicos, de característica argilo-arenoso. A geomorfologia apresenta feição tubular, dissecada por vales profundos e área de acumulação de sedimentos fluviais (SEI, 1998; SOUZA et al., 2009).

É caracterizando por ser uma região com alta biodiversidade, dada sua localização no corredor central da Mata Atlântica. A composição da vegetação é dada por campos naturais ("mussunungas"), brejos, manguezais, restingas e fragmentos de floresta ombrófila densa dispostos em áreas costeiras e preservados por 29 áreas unidades de conservação que auxiliam na proteção dos recursos socioambientais locais.

\section{Método}

Caracterizado como uma pesquisa qualitativa de campo, com caráter exploratório, utilizou-se a documentação direta, através da observação sistemática (visitas in loco) e indireta. Foram realizadas visitas durante os meses de fevereiro e março ao lixão de Porto Seguro com o intuito de executar um levantamento sistemático da disposição final dos resíduos sólidos urbanos locais e registrar os impactos ambientais existentes.

Foi realizada a Identificação da Qualidade de Aterros de Resíduos (IQR) proposta pela CETESB (2019), caracterizada como uma metodologia que considera os impactos ocasionados nos meios físicos, bióticos e antrópicos, avaliando itens referentes a estrutura de 
apoio, frente de trabalho, bermas e taludes, superfície superior, estrutura de proteção ambiental, características da área e funcionamento do local.

O IQR é um questionário estruturado que consiste na atribuição de pesos aos trinta e três parâmetros ambientais, variando entre 0 e 10 . O questionário é dividido em três subtotais, por onde realiza-se o somatório destes e divide-se por 10. O valor encontrado será considerado adequado se estiver entre 7,1 a 10,0 e inadequado caso esteja entre 0,0 e 7,0 (CETESB, 2019).

Uma ANÁLISE espacial foi realizada para verificação da disposição do lixão em relação aos aspectos socioambientais da região. Foram obtidos os vetores da hidrografia e nascente, em escala 1:100.000 do Instituto do Meio Ambiente e Recursos Hídricos da Bahia (INEMA) e identificado por meio de coordenadas geográficas as edificações que constavam no entorno da área, configurando os núcleos populacionais. As áreas de preservação permanente (APPs) foram realizadas conforme o indicado no Código Florestal Brasileiro, utilizando 30 metros para as faixas de rios e 50 metros para as nascentes (BRASIL, 2012).

Procedeu-se uma análise espacial da distância euclidiana do lixão no raio de 1000 metros do lixão, visando identificar a disposição dos aspectos socioambientais analisados. Todos os procedimentos foram realizados no software QGIS v. 2.18 e espacializados em projeção plana UTM, Datum WGS 84 no fuso $24 \mathrm{~S}$.

\section{RESULTADOS E DISCUSSÃO}

O atual local de disposição final dos resíduos sólidos urbanos em Porto Seguro encontra localizado às margens do km 40 na BR-367. Historicamente, o local foi destinado para funcionar como aterro sanitário nos anos 2000 pela Companhia de Desenvolvimento Urbano do Estado da Bahia (CONDER), com recursos doados ao município pelo Banco Mundial em comemoração aos 500 anos do Brasil. Apesar da implementação do aterro, o local foi transformado ao longo de vinte anos em um lixão a céu aberto por falta de gerenciamento adequado e possui diversas problemáticas socioambientais.

$\mathrm{O}$ aterro foi instalado para atender a uma população estimada de 251.540 habitantes e capacidade de receber $1.037 .032 \mathrm{~m}^{3}$ de resíduos. Contudo, Porto Seguro possui o agravante da população flutuante advindo do turismo local, que incrementa significativamente o volume dos resíduos gerados nos períodos de alta temporada. Atualmente, segundo estimativas do 
fluxo turístico doméstico e internacional realizado pelo MTur (2015), Porto Seguro recebe anualmente cinco vezes mais que o total de sua população fixa, estimado em mais de 1.250.000 indivíduos que visitam a cidade.

Nos períodos de baixa temporada, a produção diária de resíduos se aproxima de 150 toneladas enquanto na alta temporada esse quantitativo é elevado para 212,5 toneladas ao dia, apresentando uma média diária por habitante de $1,5 \mathrm{~kg}$. O valor diário por habitante em Porto Seguro é maior do que o encontrado no estado da Bahia que é em torno de 1,00 kg/dia e superior também a média nacional que é 1,035 kg/dia (SNIS, 2019; ABRELPE, 2018).

No âmbito local, a gestão e o manejo dos RSU são de responsabilidade da Secretaria de Trânsito e Serviços Públicos que organiza os setores de coleta e as rotas diárias. Por ter sido planejado como um aterro sanitário, foram projetados a fiscalização e controle com balança, terraplanagem, drenagem de percolado, sistema de gaseificação, abastecimento de energia elétrica e iluminação, compostagem e unidade para resíduos dos serviços de saúde, dentre outros (GEOHIDRO, 1998). Mesmo após a sua conversão em lixão, o local ainda dispõe de portaria e balança para as pesagens dos caminhões que chegam ao local, mas não são adotados critérios de controle e segurança para a descarga de resíduos quanto para os catadores.

Os Quadro 1, 2 e 3 apresentam a avaliação do IQR para o lixão de Porto Seguro. No Quadro 1, pode-se observar a qualidade do local e da disposição dos resíduos sólidos por meio da infraestrutura implantada.

Quadro 1: Avaliação da infraestrutura implantada e condições operacionais do lixão de Porto Seguro, Bahia, Brasil.

\begin{tabular}{|c|c|c|c|c|}
\hline ITEM & SUBITEM & AVALIAÇÃO & PESO & PONTOS \\
\hline \multirow{8}{*}{$\begin{array}{l}\text { Estrutura de } \\
\text { apoio }\end{array}$} & \multirow[t]{2}{*}{ Portaria, balança e vigilância } & Sim/ Suficiente & 2 & \multirow{2}{*}{2} \\
\hline & & Não/Insuficiente & 0 & \\
\hline & \multirow{2}{*}{ Isolamento físico } & Sim/ Suficiente & 2 & \multirow{2}{*}{0} \\
\hline & & Não/Insuficiente & 0 & \\
\hline & \multirow{2}{*}{ Isolamento visual } & Sim/ Suficiente & 2 & \multirow{2}{*}{0} \\
\hline & & Não/Insuficiente & 0 & \\
\hline & \multirow{2}{*}{ Acesso à frente de cargas } & Adequado & 3 & \multirow{2}{*}{0} \\
\hline & & Inadequado & 0 & \\
\hline \multirow{5}{*}{$\begin{array}{l}\text { Frente de } \\
\text { trabalho }\end{array}$} & \multirow{2}{*}{ Dimensões da frente do trabalho } & Adequado & 5 & \multirow{2}{*}{0} \\
\hline & & Inadequado & 0 & \\
\hline & \multirow{2}{*}{ Compactação dos resíduos } & Adequado & 5 & \multirow{2}{*}{0} \\
\hline & & Inadequado & 0 & \\
\hline & Recobrimento dos resíduos & Adequado & 5 & 0 \\
\hline
\end{tabular}




\begin{tabular}{|c|c|c|c|c|}
\hline & & Inadequado & 0 & \\
\hline \multirow{8}{*}{$\begin{array}{l}\text { Taludes e } \\
\text { bermas }\end{array}$} & \multirow{2}{*}{ Dimensões e inclinações } & Adequadas & 4 & \multirow{2}{*}{0} \\
\hline & & Inadequadas & 0 & \\
\hline & \multirow{2}{*}{ Cobertura de terra } & Adequada & 4 & \multirow{2}{*}{0} \\
\hline & & Inadequada & 0 & \\
\hline & \multirow{2}{*}{ Proteção vegetal } & Adequada & 3 & \multirow{2}{*}{0} \\
\hline & & Inadequada & 0 & \\
\hline & \multirow{2}{*}{ Afloramento de chorume } & Não/Raros & 4 & \multirow{2}{*}{0} \\
\hline & & Sim/Numerosos & 0 & \\
\hline \multirow{4}{*}{$\begin{array}{l}\text { Superfície } \\
\text { superior }\end{array}$} & \multirow{2}{*}{ Nivelamento da superfície } & Adequada & 5 & \multirow{2}{*}{0} \\
\hline & & Inadequada & 0 & \\
\hline & \multirow{2}{*}{ Homogeneidade da cobertura } & Sim & 5 & \multirow{2}{*}{0} \\
\hline & & Não & 0 & \\
\hline \multirow{21}{*}{$\begin{array}{c}\text { Estrutura de } \\
\text { proteção } \\
\text { ambiental }\end{array}$} & \multirow{2}{*}{ Impermeabilização do solo } & Sim/adequada & 10 & \multirow{2}{*}{0} \\
\hline & & Não/inadequada & 0 & \\
\hline & \multirow{3}{*}{$\begin{array}{l}\text { Prof. Do lençol freático (p) } x \\
\text { permeabilidade do solo }(\mathrm{k})\end{array}$} & $\mathrm{P}>3 \mathrm{~m} . \mathrm{K}<10-6 \mathrm{~cm} / \mathrm{s}$ & 4 & \multirow{3}{*}{2} \\
\hline & & $\begin{array}{l}1<=\mathrm{p}<=3 \mathrm{~m} . \mathrm{K}< \\
10-6 \mathrm{~cm} / \mathrm{s}\end{array}$ & 2 & \\
\hline & & \begin{tabular}{|l|} 
Inadequada \\
\end{tabular} & 0 & \\
\hline & \multirow{2}{*}{ Drenagem de chorume } & Sim/Suficiente & 4 & \multirow{2}{*}{0} \\
\hline & & Não/Insuficiente & 0 & \\
\hline & \multirow{2}{*}{ Tratamento de chorume } & Sim/Adequado & 4 & \multirow{2}{*}{0} \\
\hline & & Não/Inadequado & 0 & \\
\hline & \multirow[b]{2}{*}{ Drenagem provisória de águas pluviais } & Suficiente & 3 & \multirow{2}{*}{0} \\
\hline & & Insuficiente & 0 & \\
\hline & \multirow[b]{2}{*}{ Drenagem definitiva de águas pluviais } & Suficiente & 4 & \multirow{2}{*}{0} \\
\hline & & Insuficiente & 0 & \\
\hline & \multirow{2}{*}{ Drenagem de gases } & Suficiente & 4 & \multirow{2}{*}{0} \\
\hline & & Insuficiente & 0 & \\
\hline & & Adequado & 4 & \\
\hline & Monitoramento de águas subterrâneas & Inadequado & 1 & 0 \\
\hline & & Insuficiente & 0 & \\
\hline & & Adequado & 4 & \\
\hline & Monitoramento geotécnico & Inadequado & 1 & 0 \\
\hline & & Insuficiente & 0 & \\
\hline & Subtotal 1 & & 86 & 4 \\
\hline
\end{tabular}

Fonte: CETESB (2019).

Dentre os componentes que geram agravos socioambientais, destaca-se que o local se encontra em uma área de preservação permanente, com declividade inadequada, presença de catadores revolvendo os resíduos, inexistência de impermeabilização do solo e tratamento de efluentes líquidos e sem registro de licença válida.

O isolamento físico e visual é quase inexistente no local, permitindo que os resíduos sejam dispersados no entorno do lixão, entrada sem controle e pessoas no local. Conforme orientam as NBR 8.419 (ABNT, 1992) e NBR 13.896 (ABNT, 1997) um aterro deve possuir o isolamento da sua área para impedir a interferência de animais e pessoas no local e o controle de possíveis consequências nas vizinhanças. 
A área também sofre com a compactação de modo indireto que contribui para alteração das características naturais do solo e a poluição do ar em razão das partículas em suspensão provocado pelo movimento intenso de veículos. A compactação correta é um importante mecanismo para prolongar o tempo de vida útil dos locais de disposição de resíduos (KINGSLEY et al., 2016).

Os resíduos são depositados no lixão pelos caminhões e direcionado por uma escavadeira para as partes declivosas, formando montanhas de resíduos em vários pontos. Essa ação induz ao acumulo de água, do chorume e a proliferação de vetores de doenças (Figura 2). Sem estrutura para drenagem do chorume, os resíduos se decompõem e percolam sem tratamento, uma vez que as lagoas para tratamento são utilizadas para a descarga de esgoto sanitário de foças no município.

Figura 2: Amontoado de resíduos dispostos em local de declividade no lixão.

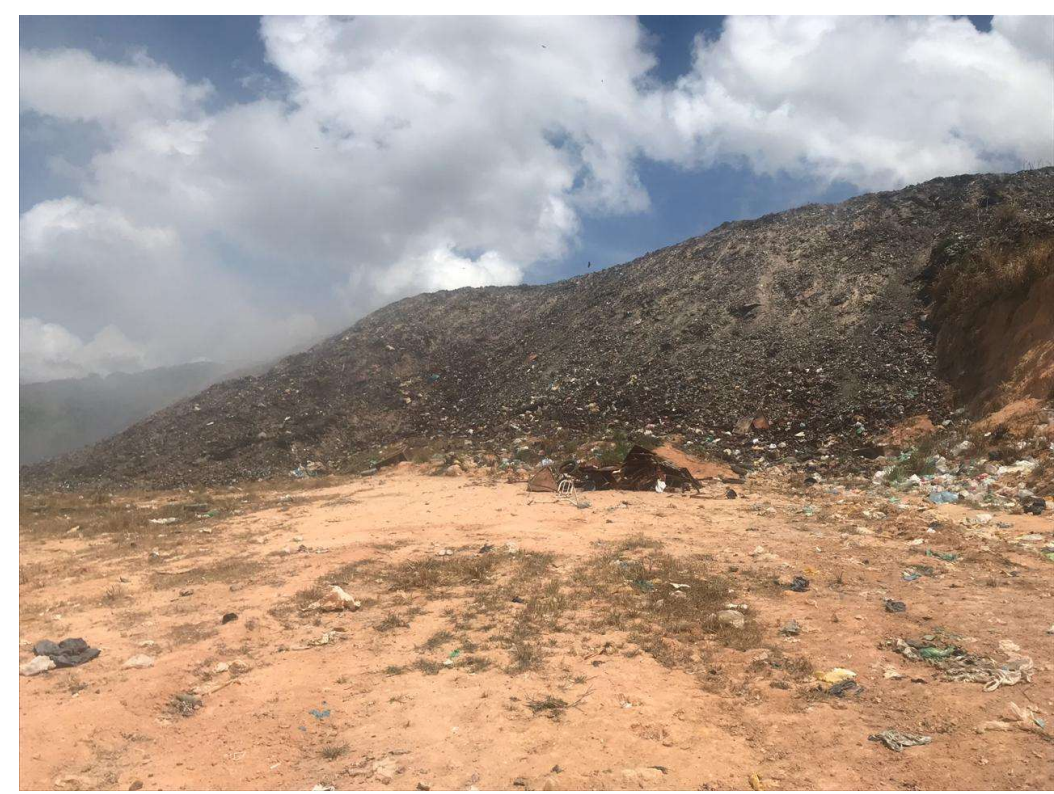

Fonte: os autores.

A ausência de nivelamento e impermeabilização do solo são ações graves na disposição final, pois conforme instruem as NBR 8.419 e NBR 13.896, a condição mínima para controlar lixiviados não-perigosos sejam constituídas de argila compactada com permeabilidade inferior a $10^{-7} \mathrm{~cm} / \mathrm{s}$ ou geomembranas de polietileno de alta densidade com espessura mínima de $1 \mathrm{~mm}$ (ABNT, 1997; 1992; NIS, 2019). Igualmente, a declividade do 
local deve ser considerada para gerenciar e controlar o escoamento superficial dos contaminantes para áreas mais distantes (IREAJA et al., 2018).

A ausência destas condições corrobora para impactos ambientais que incluem incêndios e explosões, danos à vegetação, presença de odores, contaminação das águas subterrâneas, poluição do ar e o aquecimento global (EL-SALAM e ABU-ZUID, 2015). Para Baysah et al., (2018) um caminho para impedir a contaminação por lixiviados e vazamentos das águas subterrâneas ou superficiais pode se dar com a utilização de materiais de baixa permeabilidade para revestir o fundo e as laterais dos locais. A NBR 8.419 (ABNT, 1992) também instrui que deve ser realizada a investigação geológica e geotécnica do aterro para compreender os riscos de poluição das águas e do estado de estabilidade dos maciços.

No lixão de Porto Seguro, não são realizados monitoramento de águas subterrâneas na área para avaliar os impactos ambientais ocasionados. Para Han et al., (2016) e El-Salam e Abu-Zuid (2015) os locais com ausência de coleta e descarte dos lixiviados são ameaças à qualidade das águas subterrâneas devido aos contaminantes presentes no chorume que ao se misturarem às águas superficiais ou subterrâneas, incorporam cloreto $\left(\mathrm{Cl}^{-}\right)$, sódio $\left(\mathrm{Na}^{+}\right)$e amônio $\left(\mathrm{NH}_{4}^{+}\right)$, alteram a dureza total, os sólidos dissolvidos totais (TDS) e inserem metais pesados.

Durante os períodos de chuva, o lixão apresenta bolsões de água pelo terreno e em seu entorno, evidenciando a inexistência da drenagem provisória e definitiva das águas pluviais. Silva (2004) também revela que a situação é agravada no lixão por conta do aterro ter sido implantado na calha do rio Buranhém, ocasionando nos períodos de chuva a contaminação do lençol freático e do próprio rio. Segundo o SNIS (2019), apenas 56,2\% dos 3.556 municípios brasileiros adotam estratégias para a drenagem e o manejo das águas pluviais em áreas de tratamento de resíduos, sendo uma problemática não só de Porto Seguro, mas nacional.

Para além do sistema de drenagem das águas pluviais, a implantação de um sistema de drenagem dos gases produzidos se faz necessário, pois a composição destes possui o dióxido de carbono $\left(\mathrm{CO}_{2}\right)$ e o metano $\left(\mathrm{CH}_{4}\right)$, o que eleva os impactos diariamente na cidade (KRČMAR, et al., 2017).

O Quadro 2 apresenta a avaliação da presença de animais e odores no local, para a determinação da qualidade ambiental do mesmo. 
Quadro 2: Parâmetros de avaliação.

\begin{tabular}{|c|c|c|c|c|}
\hline ITEM & SUB-ITEM & AVALIAÇÃO & PESO & PONTOS \\
\hline \multirow{10}{*}{$\begin{array}{c}\text { Outras } \\
\text { informações }\end{array}$} & \multirow{2}{*}{ Presença de catadores } & Não & 2 & \multirow{2}{*}{0} \\
\hline & & Sim & 0 & \\
\hline & \multirow{2}{*}{ Queima de resíduos } & Não & 2 & \multirow{2}{*}{0} \\
\hline & & Sim & 0 & \\
\hline & \multirow{2}{*}{ Ocorrência de moscas e odores } & Não & 2 & \multirow{2}{*}{0} \\
\hline & & Sim & 0 & \\
\hline & \multirow{2}{*}{ Presença de aves e animais } & Não & 2 & \multirow{2}{*}{0} \\
\hline & & Sim & 0 & \\
\hline & \multirow{2}{*}{ Recebimentos de resíduos não autorizados } & Não & 2 & \multirow{2}{*}{0} \\
\hline & & Sim & 0 & \\
\hline & \multicolumn{2}{|l|}{ SUBTOTAL } & 20 & $\mathbf{0}$ \\
\hline
\end{tabular}

Fonte: CETESB (2019).

Os catadores são vistos no local revolvendo os resíduos sem equipamentos de proteção individual e com condições insalubres de trabalho para a realização da coleta, expostos a situações de perigo, saúde e bem-estar. Segundo Cruvinel et al., (2019) os catadores possuem alto potencial de desenvolverem morbidades, seja por atropelamento por caminhões, incêndios, explosões e contaminações diversas.

Essa condição se eleva em Porto Seguro, pois os indivíduos que fazem uso do local não possuem instrução para a coleta, bem como se dispõem em grandes montantes de resíduos, que associados aos riscos do ambiente físico, potencializam a ocorrência de acidentes. Resíduos perigosos tecnológicos e hospitalares também são encontrados no local, com disposição inadequada, conforme NBR 10.007 (ABNT, 2004), por apresentar inflamabilidade, corrosividade, reatividade, toxicidade ou patogenicidade.

Além destas, há uma constante queima de resíduos, fumaça tóxica e a presença de animais. Garcia e Candiani (2017) aponta ser comum a presença de cachorro doméstico (Canis familiaris), cavalo (Equus caballus), boi (Bos taurus) e gato doméstico (Felis catus). Em Porto Seguro, além destes as condições climáticas ainda favorecem a presença de escorpiões e cobras nos resíduos depositados, aumentando o risco aos catadores.

Ainda que não sejam regulamentados, os catadores são responsáveis por destinarem a reciclagem de resíduos como o papel, papelão, alumínio e o PET que ficariam depositados sem o manejo correto. Esse papel social de reciclagem indireta favorece a redução dos resíduos na cidade e o direcionamento para novas formas de produção. A cidade ainda não possui usinas e cooperativas de reciclagem formalizadas, o que impede o maior aproveitamento dos resíduos que, em grande parte, são potenciais para a reciclagem pois o 
consumo turístico se dá diretamente por produtos de fácil consumo e com embalagem plástica.

O Quadro 3 aponta a avaliação das características locais em relação à urbanização, corpos d'água e vida útil.

Quadro 3: Parâmetros de avaliação das características do local.

\begin{tabular}{|c|c|c|c|c|}
\hline ITEM & SUB-ITEM & AVALIAÇÃO & PESO & PONTOS \\
\hline \multirow{8}{*}{ Características da área } & \multirow{2}{*}{ Proximidades de núcleos habitacionais } & $\geq 500 \mathrm{~m}$ & 2 & \multirow{2}{*}{0} \\
\hline & & $<500 \mathrm{~m}$ & 0 & \\
\hline & \multirow{2}{*}{ Proximidades de corpos d'água } & $>=200 \mathrm{~m}$ & 2 & \multirow{2}{*}{0} \\
\hline & & $<200 \mathrm{~m}$ & 0 & \\
\hline & \multirow{2}{*}{ Vida útil da área } & $2<\mathrm{x}<=5$ anos & & \multirow{2}{*}{-} \\
\hline & & $>5$ anos & $\mathrm{x}$ & \\
\hline & \multirow{2}{*}{ Restrições legais ao uso do solo } & Sim & & \multirow{2}{*}{ - } \\
\hline & & Não & $\mathrm{x}$ & \\
\hline \multicolumn{3}{|c|}{ SUBTOTAL 3} & 4 & $\mathbf{0}$ \\
\hline
\end{tabular}

Fonte: CETESB (2019).

Embora esteja situado distante do núcleo urbano, o lixão possui núcleos habitacionais em seu entorno, incentivado pela possibilidade de renda diária com a catação de resíduos. Quanto ao tempo de vida útil do aterro, a NBR 13.896 (ABNT, 1997) instrui que seja superior a 10 anos, entretanto, em Porto Seguro o local de disposição final dos RSU deixou de funcionar como aterro sanitário passando a funcionar como lixão a céu aberto.

A duração da vida útil de um aterro sanitário está diretamente relacionada a existência de infraestrutura, condições operacionais e gestão adequadas, garantindo que ocorra o seu funcionamento adequado e a diminuição dos impactos causados ao meio ambiente. Ainda que a disposição dos resíduos tenha deixado de ocorrer de modo ambientalmente adequado, como estabelece a PNRS, não há registros de monitoramentos durante todos esses anos.

As condições operacionais, de infraestrutura e as características ambientais que a área se encontra sugerem uma crise local no sistema vigente de disposição final dos resíduos. Isso, porque, além do modo inapropriado que os resíduos são despejados no lixão, tem-se o agravante do incremento significativo atribuído aos turistas que visitam o município e o aumento considerável de resíduos sólidos.

Com base nas avaliações realizadas, a qualidade ambiental do lixão e a disposição dos resíduos sólidos em Porto Seguro obteve um índice de 0,4 , este valor classifica a área com um 
índice inadequado, corroborando para indicar que o modo de disposição final em Porto Seguro carece de readequação conforme orientam as políticas públicas e as NBR 13.896 (ABNT, 1997) e NBR 8.419 (ABNT, 1992).

A avaliação espacial da distribuição dos aspectos socioambientais do entorno do lixão é apresentada na Figura 3.

Figura 3: Distância Euclidiana do lixão de Porto Seguro, Bahia em relação aos aspectos socioambientais do seu entorno.
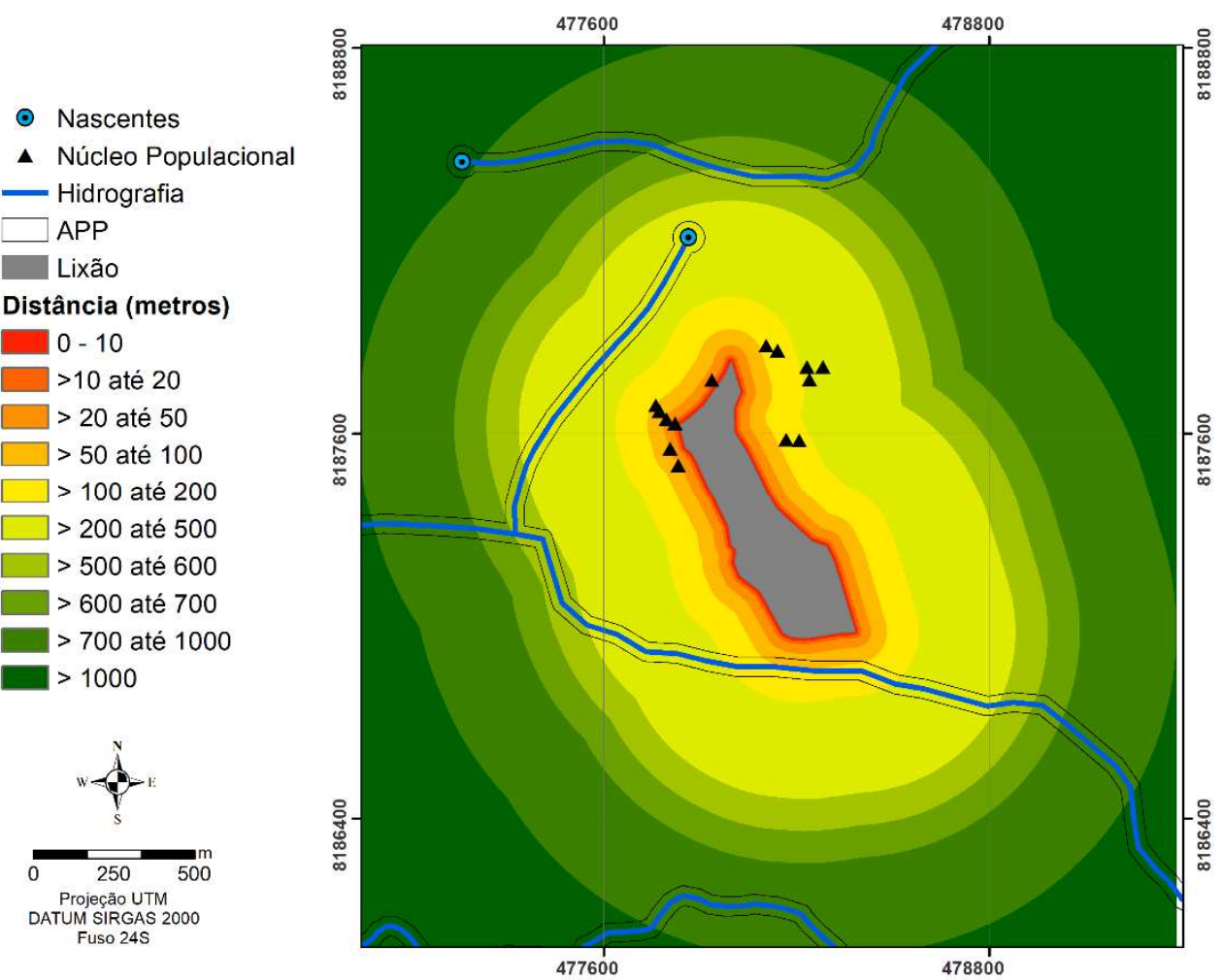

Fonte: elaborado pelos autores.

Observou-se que desde a presença de habitações quanto as existências de hidrografias podem ser encontradas a pelos menos 1000 metros do lixão, revelando a facilidade da contaminação de corpos hídricos, indivíduos e recursos naturais com os derivados dos resíduos descartados incorretamente. Estudo realizado por Han e colaboradores (2016) apontam que as contaminações das águas subterrâneas em aterros sanitários aparecem sobretudo dentro de 1000 metros do local, sendo que grande parte da contaminação grave ocorre dentro de 200 metros. 
A presença de duas nascentes, sendo uma delas com distância de 406 metros, evidencia como os recursos hídricos podem ser contaminados em seu curso inicial enquanto ao sul do lixão é observado corpo d'água distante a 97 metros e que recebe os efluentes da estação de tratamento além de chorume, metais pesados e outros derivados do descarte de resíduos. De acordo com a norma NBR 13.896 (ABNT, 1997), a distância mínima de 200 metros deveria ser respeitada, aliada a impermeabilização do solo e implantação de sistemas de drenagem para todos os líquidos gerados, evitando assim possíveis contaminações.

Em 836 metros do lixão encontra-se o rio Buranhém, principal rio da região e de importância significativa para o Território do Descobrimento, já que é utilizado para abastecimento de água, pesca artesanal, irrigação e transporte hidroviário. A avaliação da qualidade do rio, prioritariamente nesta região, deve ser encorajada para identificar os padrões de uso e classificação da água, conforme resolução CONAMA 357/2005. Associado, as APPs devem garantir a preservação dos recursos hídricos apresentando vegetação natural e sua proximidade com o lixão também pode induzir a supressão vegetal, a contaminação de espécies vegetais e do solo. Vale ressaltar que as APPs podem auxiliar no atendimento da redução de erosão, da formação de poeira e transporte de odores, conforme NBR 13.896 (ABNT, 1997).

Os núcleos populacionais no local são os que mais se aproximam do lixão, resultados do povoamento dos catadores que obtém sua renda dos resíduos descartados, por onde os domicílios localizam-se entre 14 m e 268 m de distância. Segundo aponta a NBR 13.896 (ABNT, 1997) as áreas circunvizinhas aos locais de descarte devem apresentar núcleos populacionais distantes em um raio acima $500 \mathrm{~m}$ visando evitar problemas de insetos e animais nocivos, poeira, fogo, tráfego, ruído e desvalorização imobiliária.

Contudo, as instalações desses núcleos foram incentivadas pela posterior transformação do aterro em lixão, o que confirma ausência de mecanismos de gerenciamento de resíduos sólidos na cidade mas induz a necessária orientação da população e estratégias para atenção à saúde e bem estar-social. Para Donevska et al. 2012, a proximidade com assentamentos urbanos e rurais pode causar efeitos ambientais negativos.

O SNIS (2019) orienta como estratégias, além da mudança para um aterro sanitário, que ocorra a remediação e fechamento do lixão, bem como, a recuperação da área em uso com condições sanitárias e ambientais apropriadas para instalação de um aterro sanitário no local para que continue a receber resíduos. Ireaja (2018) sugere que seja aplicada a 
metodologia conhecida como 3R's: Reduzir, Reutilizar e Reciclar os resíduos biodegradáveis para diminuir o montante que chegam até os aterros.

Atrelado a estas estratégias, considera-se pertinente a previsão da estimativa de população flutuante, o monitoramento de curto e longo prazo do aterro que se encontra em uso e do que venha a ser implantado. O monitoramento permite que se conheça o grau de contaminação do aterro, bem como, possibilita acompanhar os níveis das emissões de gases e do percolado que é gerado como subproduto da decomposição dos resíduos, fornecendo subsídios aos gestores para diminuir os impactos causados ao meio ambiente.

Diante dos desafios enfrentados pelo município de Porto Seguro, devem ser considerados diversos aspectos para escolha e implantação de um novo aterro. Segundo Baierle et al., (2016) deve-se levar em conta aspectos como a localização, as características topográficas, os tipos de solo, dados pedológicos e geomorfológicos, informações sobre as águas subterrâneas e superficiais, dentre outras, durante a tomada de decisão. Lourenço et al., (2015) acrescenta que no estudo de implantação de áreas para disposição final deve considerar aspectos técnicos, ambientais e socioeconômicos, que apresenta alterabilidade e correlação no espaço estudado.

No contexto atual, o que se verifica no município é a ausência de perspectivas para a resolução da situação. Essa é, também, uma realidade enfrentada por muitos municípios brasileiros, ainda que tenham sido criadas políticas públicas que incentivem a disposição ambientalmente adequada e criminalizem os lixões. Conforme destacam Assad e Siqueira (2016), o obstáculo que dificulta tal política se tornar mais sólida está ligada a ausência de recursos, de quadros técnicos e gerenciais capacitados, para além da atuação política.

\section{CONSIDERAÇÕES FINAIS}

O atual local de disposição final dos resíduos sólidos urbanos de Porto Seguro apresenta condições inadequadas para tal finalidade e não atende aos requisitos mínimos nas normas técnicas para gerenciamento de resíduos quanto aos aspectos socioambientais. A situação vivenciada pelo município serve de exemplo de que a implantação e gestão de um aterro sanitário deve possuir monitoramento contínuo durante todo o seu período de vida útil e após o seu encerramento, além de considerar fatores predominantes na região, como é o caso da população flutuante turística. 
Os estudos das condições operacionais, de infraestrutura e características da área, bem como a análise espacial realizada, indicaram ausência de impermeabilização do solo, drenagem do chorume e gases, recobrimento dos resíduos, isolamento físico e visual trazem consequências diretas ao ecossistema local, itens primordiais ao correto funcionamento do local e redução de impactos. A presença de catadores na condição insalubre potencializa a vulnerabilidade socioambiental provocada pela gestão ineficaz vigente no município e amplia a necessidade de adoção de medidas mitigadoras para o local.

A avaliação de impacto ao possibilitar a análise detalhada do lixão de Porto Seguro também funciona como ferramenta de apoio a decisão para a gestão local. Os resultados obtidos induzem a caminhos lógicos para reverter a problemática atual e apontam a necessidade de se estabelecer estratégias para reverter o quadro da disposição dos resíduos no município, sendo necessário a adoção de medidas como o monitoramento do local, a implantação de um novo aterro sanitário que atenda a demanda local e o engajamento dos gestores públicos para garantir a gestão e o manejo adequado dos resíduos sólidos urbanos gerados.

\section{REFERÊNCIAS}

ABRELPE. Associação Brasileira de Empresas de Limpeza Pública e resíduos Especiais (São Paulo). Panorama dos Resíduos Sólidos no Brasil 2017. São Paulo: Abrelpe, 2018. 74 p.

ARRIETA, G.; REQUENA, I.; TORO, J.; ZAMORANO, M. Adaptation of EVIAVE methodology for monitoring and follow-up when evaluating the environmental impact of landfills. Environmental Impact Assessment Review, v. 56, p. 168 - 179, 2016.

ASSAD, L.; SIQUEIRA, T. Lixões continuam por toda parte. Revista Ciência e Cultura, São Paulo, v. 68, n. 2, p. 08-10, junho 2016.

ASSOCIAÇÃO BRASILEIRA DE NORMAS TÉCNICAS. NBR 8.419: Apresentação de projetos de aterros sanitários de resíduos sólidos urbanos. Rio de Janeiro: ABNT, 1992.

ASSOCIAÇÃO BRASILEIRA DE NORMAS TÉCNICAS. NBR 13.896: Fixa condições mínimas exigíveis para projetos, implantação e operação de aterros de resíduos sólidos não perigosos. São Paulo: ABNT, 1997.

ASSOCIAÇÃO BRASILEIRA DE NORMAS TÉCNICAS. NBR 10.004: Estabelece critérios de classificação e os códigos para identificação dos resíduos de acordo com as suas características. Rio de Janeiro: ABNT, 2004. 
BAIERLE, B.; MUNIZ, M. S.; TOMAZONI, J. C.; MANOSSO, F. C. Seleção de área adequada para implantação de aterro sanitário no município de Marmeleiro - PR, através de técnicas de geoprocessamento. Revista Engenharia Ambiental - Espírito Santo do Pinhal, v. 13, n. 2 p. $110-127$, jul./dez. 2016

BAYSAH, Y. C.; NGUMBU, R. S.; FAYIA, A. K.; MOORE, A. S.; TOE SR, J. T.; JALLAH JR, J. K. Geotechnical characterizacion of soils for use as landfill liner: a case study of soil samples from the Paynesville sandstone farmigton river formation, Liberia. Res. Sci. Technol. November-December-2018; 4(11): 70-75

BRASIL. Lei ${ }^{0}$ 6.938, de 31 de agosto de 1981. Dispõe sobre a Política Nacional de Meio Ambiente, seus fins e mecanismos de formulação e aplicação, e dá outras providências. Diário Oficial da União. Brasília, DF, set. 1981.

BRASIL. Lei $\mathrm{n}^{\mathrm{o}}$ 12.305, de 2 de agosto de 2010. Institui a Política Nacional de Resíduos Sólidos; altera a lei $\mathrm{n}^{\circ}$ 9.605, de 12 de fevereiro de 1998; e dá outras providências. Diário Oficial da União. Brasília, DF, ago. 2010.

BRASIL. Lei $n^{\circ} 12.651$, de 25 de maio de 2012. Dispõe sobre a proteção da vegetação nativa; altera as Leis $\mathrm{n}^{\circ} \mathrm{s}$ 6.938, de 31 de agosto de 1981, 9.393, de 19 de dezembro de 1996, e 11.428, de 22 de dezembro de 2006; revoga as Leis $\mathrm{n}^{\circ} \mathrm{s}$ 4.771, de 15 de setembro de 1965, e 7.754, de 14 de abril de 1989, e a Medida Provisória n ${ }^{\circ}$ 2.166-67, de 24 de agosto de 2001; e dá outras providências. Diário Oficial da União. Brasília, DF, mai. 2012.

BRASIL. Ministério das Cidades. Sistema Nacional de Informações sobre Saneamento: Diagnóstico do Manejo de Resíduos Sólidos Urbanos - 2017. Brasília: MCIDADES, 2019.

CETESB, COMPANHIA AMBIENTAL DO ESTADO DE SÃO PAULO. Inventário Estadual de Resíduos Sólidos Urbanos de 2018. Coordenação e redação Maria Heloisa P. L. Assumpção; equipe técnica Marilda de Souza Soares ... [et al.]; colaborador Fernando Antônio Wolmer - São Paulo: CETESB, 2019.

CRUVINEL, V. R. N.; MARQUES, C. P.; CARDOSO, V.; NOVAES, M. R. C. G.; ARAÚJO, W. N.; ÂNGULO-TUESTA, A.; et al. Health conditions and occupational risks in a novel group: waste pickers in the largest open garbage dump in Latin America. BMC Public Health, v. 19, n. 581, 2019.

EL-SALAM, M. M. A.; ABU-ZUID, G. I. Impact of landfill leachate on the groundwater quality: a case study in Egypt. Journal of Advanced Research, v. 6, p. 579-586, 2015.

FELICORI, T. C.; MARQUES, E. A. G.; SILVA, T. Q.; PORTO, B. B.; BRAVIN, T. C.; SANTOS, K. M. C. Identificação de áreas adequadas para a construção de aterros sanitários e usinas de triagem e compostagem na mesorregião da Zona da Mata, Minas Gerais. Revista de Engenharia Sanitária e Ambiental, Rio de Janeiro, v. 21, n. 3, p. 547-560, set 2016.

FERREIRA, R. G. Impactos ambientais decorrentes do lixão da cidade de Condado - PB. Revista Geografia, Ensino \& Pesquisa, v. 21, n. 3, p. 142 - 151, 2017. 
GARCIA, D. C.; CANDIANI, G. Diagnóstico dos inventários de fauna em estudos de impacto ambiental de aterros. Revista Brasileira de Ciências Ambientais, n. 45, p. 100-114, set 2017.

GEOHIDRO. Projeto da disposição final (aterro sanitário) de Porto Seguro - BA. 1998. Disponível: $\quad<$ http://www.geohidro.com.br/project/projeto-da-disposicao-final-aterrosanitario-da-cidade-de-porto-seguro/>. Acesso em jan. 2020.

HAN, Z.; MA, H.; SHI, G.; HE, L.; WEI, L.; SHI, Q. A review of groundwater contamination near municipal solid waste landfill sites in China. Science of the Total Environment, v. 569, p. $1255-1264,2016$.

IBGE - Instituto Brasileiro de Geografia e Estatística. Pesquisa Nacional por Amostra de Domicílios: síntese de indicadores 2010. Porto Seguro: IBGE.

IREAJA, N. A.; OKEKE, O. C.; OPARA, A. I. Sanitary landfills: geological and environmental factors that influence their siting, operation and management. International Institute of Academic Research and Development, v. 4, n. 5, 2018.

KINGSLEY, E. N.; PASCHAL, I. O.; JUDE, E. O. Assessment of landfill sites for solid waste management in Delta state, Nigeria. Journal of Environment and Waste Management, v. 3, n. 1, p. 116 - 122, mai. 2016.

KRČMAR, D.; TENODI, S.; GRBA, N.; KERKEZ, D.; WATSON, M.; RONČEVIC, S.; DALMACIJA, B. Preremedial assessment of the municipal landfill pollution impact on soil and shallow groundwater in Subotica, Serbia. Science of the Total Environment, v. 615, p. $1341-1354,2018$.

LIMA, G. F. C. Consumo e resíduos sólidos no Brasil: as contribuições da educação ambiental. Revista Brasileira de Ciências Ambientais, v. 37, p. 47-57, 2015.

LOURENÇO, R. W.; CUNHA E SILVA, D. C.; SAlES, J. C. A.; MEDEIROS, G. A.; OTERO, R. A. P. Metodologia para seleção de áreas aptas à instalação de aterros sanitários consorciados utilizando SIG. Revista Ciência e Natura, v. 37, n. 3, p. 122-140, set-dez 2015.

MTur - Ministério do Turismo. Parâmetros de consulta: Nordeste/Bahia, Costa do Descobrimento, Porto Seguro. Categorização dos municípios das regiões turísticas do mapa do turismo brasileiro conforme Portaria no 144, de 27 de agosto de 2015.

PNUD - PROGRAMA DAS NAÇÕES UNIDAS PARA O DESENVOLVIMENTO; IPEA INSTITUTO DE PESQUISA ECONÔMICA E APLICADA; FUNDAÇÃO JOÃO PINHEIRO. Atlas de desenvolvimento humano do Brasil de 2013. 2013.

Disponível em: <http://www.atlasbrasil.org.br/2013/>. Acesso em: jan 2020.

SILVA, I. R. Praias da Costa do Descobrimento: uma contribuição para a gestão ambiental. Tese de Doutorado do Programa de Pós-Graduação em Geologia da Universidade Federal da Bahia, 2004. 
SNIS - SISTEMA NACIONAL DE INFORMAÇÕES SOBRE SANEAMENTO. Série

Histórica: Resíduos Sólidos. 2018.

SOUZA, C. M. P; MOREAU, A. M. S. S.; FONTES, E. O. Zoneamento geoambiental e transformações da paisagem dos municípios Porto Seguro e Santa Cruz Cabrália - BA. IX Seminário de Pós-Graduação em Geografia da UNESP Rio Claro, 2009.

TALALAJ, I. A.; BIEDKA, P. Use the landfill water pollution index (LWPI) for groundwater quality assessment near the landfills sites. Environmental Science and Pollution Research, v. 23, p. 24601-24613, 2016.

TURRA, A.; AMARAL, A. C. Z.; CIOTTI, A. M.; ROSSI-WONGTSCHOWSKI, C. L. D. B.; SCHAEFFER-NOVELLI, Y.; MARQUES, A. C.; et al. Avaliação de impacto sob uma abordagem ecossistêmica: ampliação do porto de São Sebastião. Revista Ambiente \& Sociedade, v. 10, n. 3, p. 159-178, jul-set 2017.

USEPA. United States Environmental Protection Agency. Advancing Sustainable Materials Management: 2015 Fact Sheet. Assessing Trends in Material Generation, Recycling, Composting, Combustion with Energy Recovery and Landfilling in the United States. Jul 2018. Disponível em: <https://www.epa.gov/sites/production/files/201807/documents/2015_smm_msw_factsheet_07242018_fnl_508_002.pdf $>$. Acesso em: jan. 2020. 